\title{
Science, Nature and Control: Interpreting Mechanics' Institutes
}

\section{Citation}

Shapin, Steven and Barry Barnes. 1977. Science, nature and control: Interpreting mechanics' institutes. Social Studies Of Science 7(1): 31-74.

\section{Published Version}

http://dx.doi.org/10.1177/030631277700700109

\section{Permanent link}

http://nrs.harvard.edu/urn-3:HUL.InstRepos:3353819

\section{Terms of Use}

This article was downloaded from Harvard University's DASH repository, and is made available under the terms and conditions applicable to Other Posted Material, as set forth at http:// nrs.harvard.edu/urn-3:HUL.InstRepos:dash.current.terms-of-use\#LAA

\section{Share Your Story}

The Harvard community has made this article openly available.

Please share how this access benefits you. Submit a story.

\section{Accessibility}




\title{
Science, Nature and Control: Interpreting Mechanics' Institutes
}

\author{
Steven Shapin and Barry Barnes
}

The study of the Mechanics' Institute movement of Great Britain has always been marginal to three academic communities - the history of education, the history of science and the history of technology. The greatest quantity of empirical historical work on the Institutes, and some of the most relevant general orientations, comes from historians of education. Some of these scholars have made convincing cases for approaching the movement, alike with other early nineteenthcentury educational interventions, by setting it against the social and political context of an industrializing society. ${ }^{1}$ However, while the approach via the social history of education has been rewarding, many of its practitioners have felt that the scientific and technical curricula of the Mechanics' Institutes somehow made them 'special cases', immune from contextual analysis in the same terms as non-scientific institutions. Interpreting the purposes of Mechanics' Institutes would be the work of historians of science.

In fact, the history of the Institutes has been no more than a peripheral concern for the history of science. Its individualistic epistemology has suggested that 'what people believe' can only be either a simplification of scientific truth or a corruption of it; hence the diffusion of scientific knowledge to 'popular' audiences has been considered only in terms of 'filtration' or 'adulteration'. Viewed from this perspective, instead of as collective representations needing understanding in their own right, popular beliefs about nature have been only of marginal interest. Exalted above the scope of their contextual

Authors' address: Science Studies Unit, University of Edinburgh, 34 Buccleuch Place, Edinburgh EH8 9JT, Scotland, UK. 
methods by historians of education, they have remained unworthy material for the analyses and exegeses of historians of science.

In contrast, the Institutes have been justified and vindicated by historians of technology - not, however, on grounds which stand up well to empirical investigation. The Mechanics' Institutes, so they said, brought science to the service of industry, answered the demand for technical education from the superior artisan and operative, performed important economic functions in an industrializing society, and were the forerunners of the modern technological university. But, as the social historians of education have already shown, the utilitarian, 'demand-pull' interpretation of the Institutes is certainly partially, and perhaps generally, misleading. The founding of the Mechanics' Institutes, like most British educational policy in the early nineteenth century, was mainly informed by an interest in social control.

Our purpose in this paper is to show how the founders of British Mechanics' Institutes thought a scientific education would aid in the social control of those artisans who were their designated target. We intend to elicit from the public statements of the movement's leaders the basis and structure of their own belief that a regimen of scientific education for certain members of the working class would render them, and their class as a whole, more docile, less troublesome, and more accepting of the emerging structure of industrial society.

We cannot here hope to marshal all possible evidence establishing the credibility of the link between the Institute movement and a practical interest in social control. Nor will space allow us thoroughly to refute the credibility of the utilitarian interpretation of the Institutes. We shall rely upon other authors for support here and accept the social control link as our starting point. Our main proposal is to develop an interpretation of 'the scheme of things' in terms of which the proponents of popular education in science might plausibly believe that knowledge of a certain kind could control people. We shall go on to show how our interpretation provides an integrated explanation of the relationship between the Institutes' original control purposes and the nature of the scientific knowledge presented in their curricula. Finally, since the problem of how knowledge is to be related to control is a very general one, we shall draw out some of the wider implications of the explanation we provide, and conclude by showing how the problem of interpreting Mechanics' Institutes relates to some of the most basic problems of the social anthropologist and the sociologist of knowledge. 


\section{HISTORICAL RESUME}

Included in the designation 'Mechanics' Institute' (or, less commonly, 'School of Arts') was a variety of early to mid-nineteenth-century foundations, all initially created to teach aspects of the sciences to sections of the British working classes. The study of the Institutes is still in its infancy: there is still no modern book-length account of any individual British Institute, and many of the questions we shall raise go perhaps too far beyond what can be resolved by available empirical studies. ${ }^{2}$ Still, sufficient work has now been done to establish many features of the movement's history.

There is some controversy about what constituted the earliest example of a Mechanics' Institute, but the choice between favoured candidates need not concern us here. ${ }^{3}$ What matters is that the few foundations in existence before 1825 provided a model and inspiration leading to a rapid proliferation of this kind of organization over the next two decades. A major catalyst of this sudden explosion was the 1825 publication by Henry Brougham of his Practical Observations upon the Education of the People. ${ }^{4}$ This very widely circulated pamphlet publicized the endeavours of the existing enterprises of London, Edinburgh, Glasgow and other Northern cities, and set down a general plan for establishing and managing Institutes throughout Great Britain. ${ }^{5}$ Immediately following its appearance, new Institutes sprang up in profusion, encouraged and supported by Brougham's Society for the Diffusion of Useful Knowledge and its numerous provincial branches. ${ }^{6}$ Sponsored by local coteries of utilitarians, Unitarians, philosophical radicals of various hues, and reform-minded civic leaders, Institutes had appeared in practically every sizeable British town by the 1840 s. By 1851 , according to one, apparently reliable, account, there were over 700 'Literary and Mechanics' Institutes' in Great Britain and Ireland, with over 120,000 members. ${ }^{7}$ This appears to mark the high point of their expansion.

Demographically, the Institutes were predominantly urban phenomena, intimately linked with industrialization and its consequent social situations. A map of industrial urbanization in Britain would overlap nicely with a map of the distribution of Mechanics' Institutes ${ }^{\mathbf{8}}$; they were particularly numerous in Lancashire and Yorkshire. The most successful were found in the most vigorous industrial and commercial centres: Glasgow, Manchester, Liverpool, Leeds, Newcastle-upon-Tyne all had at least one well-supported Mechanics' Institute founded in the 1820 s. 
Except for a very few known cases the Institutes were not projected by the same sort of people they were intended to serve. ${ }^{9}$ Rather, they were in general organized by interested members of the middle classes for specified sectors of the working classes. At the national level, as already mentioned, the political allegiance of those who advocated and established Mechanics' Institutes was predominantly Whig to philosophical radical, so that one very frequently finds the same individuals marching under the banners of 'scientific education for the working classes', 'the Reform Bill', and 'opposition to the Corn Laws' ${ }^{10}$ At the local level, projectors of Mechanics' Institutes may be found among the same sorts of occupational groups as patronized the provincial scientific societies (the 'Lit and Phils') of the Midlands and North of England: physicians, surgeons and apothecaries; dissenting divines; 'enlightened' manufacturers and merchants. Having found the cultivation of science appropriate to their own situation in local society, they now found compelling arguments for the propriety and value of science for the lower orders.

It should be emphasized that those who advocated this form of education possessed a finely graded map of society. To speak of the Mechanics' Institutes as providing science for 'the working class', as a number of their historians do, misses an important discrimination made by the actors themselves, and puts us in danger of losing much of the sense of purpose behind the entire enterprise. People in the 1820 s spoke of 'the working classes' as encompassing a number of discrete sectors. Thus, when advocates of Mechanics' Institutes referred to 'artisans', or to 'operatives', or 'mechanics', they did not mean to refer to the 'working classes' as an entirety. Rather, they were pointing to occupational sub-categories which, to them, possessed 'known' attributes - economic, social, moral and intellectual. They had it in mind to provide an educational regimen for these sub-groups only, and not for 'the working classes' as a whole. ${ }^{11}$ This precise identification of the target of the proposed educational programme is crucial to understanding why the enterprise was deemed appropriate, why some sectors of British society resisted it, and why the curriculum took the form it did.

In view of the audience intended for the Institutes by their advocates in the $1820 \mathrm{~s}$, it is of some interest to note that many of the complaints which began to be heard as early as the 1830 s, rising to a crescendo in the early 1850 s, charged that the Mechanics' Institutes were no longer serving 'mechanics'. They were, it was widely said, becoming increasingly petty-bourgeois in character; shop-keepers 
and clerks were said to be replacing artisans and mechanics. ${ }^{12}$ In the present state of historical research it is unproven whether the great majority of the Institutes ever, in fact, reached the type of audience which their founders desired. Certainly, membership lists of various Institutes suggest that, by the 1830 s and 1840 s, the petty-bourgeoisie predominated. But whether they took over the Institutes or whether they always outnumbered the mechanics and artisans must remain uncertain for the great majority of organizations. We can, however, say with confidence that, given the publicly stated aims of the Institutes' founders and the specified nature of their originally intended clientele, the movement was a failure.

Fortunately, the lack of data on the Institutes' later careers, however regrettable, does not seriously affect our present purposes. We are primarily concerned to study the initial impetus to the foundation of the Institutes, the purposes they were intended to fulfil, and the reasons for the original design of their curricula. This involves concentration on the Institutes' pre- and very early history when the aims of founders and supporters were most vocally propagandized. Although their subsequent failure is, on our account, very much to be expected, how precisely it came about is of no great importance to our argument.

\section{PRACTICAL CONTROL PROBLEMS}

Perhaps the strongest impression one takes away from the voluminous pamphlet literature which spewed forth with the birth of the Institute movement is of the quaintly archaic rhetorical formulations by which founders assured themselves (and their audience) that a scientific education for the artisan and operative would result in their moral improvement. The idiom of this rhetoric of justification is of some interest.

The minds of the working classes were assumed to be occupied 'by objects of sense', so much so that 'when they seek for recreation, they do it in a sensual way'.13 Drunkenness, debauchery and promiscuity characterized workers' behaviour, according to those who advocated a remedy in scientific education. The curriculum of the Mechanics' Institutes would cope with this situation by rescuing 'them from this temptation, by providing them with pursuits above the grossness of sensuality': 
[it] reclaimed many from the habits of vice. It provided them with safe and rational recreation, which might otherwise be sought in scenes of low debauchery, and it had the effect of promoting the strength and prosperity of the country in general.14

In North Staffordshire and in Edinburgh the rhetoric was practically identical: ' . . . the pursuit of knowledge is advantageous to the working man, by rendering him superior to habits of drinking, [and] by introducing him to new and purer pleasures, and all without any necessary ill consequences to his superiors'. ${ }^{15}$ There was assumed to be something specially effective about scientific education in accomplishing this job of uplift and control. '... By studying the properties of matter, and the laws of nature, it will lead them to reverence their God, on viewing scientifically his wonderful works', thereby rendering workers 'better husbands, fathers, and brothers' ${ }^{16}$ The study of the natural world, through scientific accounts, would increase contentment by displaying 'those beautiful contrivances, by which the Almighty has adapted the whole system of the universe to the comfort and advantage of man, and which at one display the infinite wisdom and good ness of an all-perfect Being'. 17

The Rev Thomas Chalmers saw science and religion as being alternative means of achieving the same effect:

There obtains a very close affinity between a taste for science, and a taste for sacredness. They are both of them refined abstractions from the grossness of the familiar and ordinary world; and the mind which relishes either has achieved a certain victory of the spiritual or the intellectual, over the animal part of our nature. The two resemble in this, that they make man a more reflective and a less sensual being, than before; and, altogether, impress a higher cast of respectability on all his habits, and on all his ways. 18

Scientific accounts would therefore aid in making a convincing display of a moral vision. Thus, a scientific education was intended to have both a general and a special uplifting and controlling outcome. In general, scientific study was to be an intellectual pastime which could be an appropriate alternative to socially undesirable activities, such as drinking and extra-marital sex. More specifically, the study of the natural world would point out laws, relationships and the presence of design of which the worker would otherwise be unaware. And in being thus brought to perceive this rational organization of nature, he would perceive (metaphorically or directly) the rational organization of society also, in its harmonious relationship with the natural world. The effect of this perception would be to render 
behaviour and values more stable.

We might wonder why natural science, rather than the edification of clerics and moralists, was thought particularly appropriate as a source of uplift. ${ }^{19}$ The reason, we are frequently told, lay in its objectivity and value-neutrality. If the disruptive political literature of the working classes could not be supplanted by a diet of middle class moralizing (as indeed it could not be), ${ }^{20}$ then perhaps it could be replaced by scientific works at least free of disturbing political implications. Moreover, unlike the various brands of political economy and theology, natural science did not divide the middle and upper classes. Whigs and Tories could, hopefully, collaborate in institutionalizing that diffusion of the natural sciences which would render the working classes 'more unwilling to engage in any bad or hazardous enterprises'. 'These are effects which could benefit no desparate political party', argued the Whig Leonard Horner in an Edinburgh context rent by party-ideological cleavages. Who among the higher orders could object to withdrawing the artisans 'from angry political discussion, begun in the workshop and adjourned to the alehouse'? 21 Controversial religious, political and political economy literature was almost universally banned from the Institutes' libraries. ${ }^{22}$ In the light of the uncontrollable circulation of political, sentimental and pornographic literature among the working classes at the time, the appeal of a scientific regimen to 'crowd out' bad influences was considerable. Scientific education could therefore control the working classes by substituting good currency for bad. But at best the actual nature of the scientific curriculum would have an active stabilizing effect.

This rhetoric of control reflects an authentic and deep rooted concern. ${ }^{23}$ The ever-pressing problem of social control had become, at the beginning of the century, particularly acute with regard to the urban working classes. ${ }^{24}$ For industrial employers, and the bourgeoisie generally, the problem of managing the technology and economics of the industrialization process was paralleled by the equally significant problem of managing the behaviour of the labour force. ${ }^{25}$ And, however much they made of 'laissez-faire' and the rest, the bourgeoisie were well aware that the evolution of a society which would serve their interests demanded active supervision and careful intervention.

There were, moreover, no exemplars of successful control. No-one knew what a stable society based on an industrial city would look like. There was a pre-industrial agrarian society that, at least in useful myth, was stable, and could be pointed to as a model of a society 
'that worked'; but the 'green and pleasant' country-society was in the process of being destroyed, drained and distorted by the great industrializing cities. By comparison with the dominant image of agrarian society, the social arrangements of the industrial cities did not seem to be working very well. In particular, the practical moral and political management of the working classes seemed intensely problematic.

What were the practical problems of social management people talked about in the British cities of the 1820s, in the environments where Mechanics' Institutes flourished? They talked about the practical problems of working-class crime, irreligion, immorality, improvidence, and, endlessly, about drunkenness. ${ }^{26}$ They talked about the behaviour and what they held to be the values (or lack of values) underlying the behaviour patterns which most ill-fit a smoothly functioning industrial society. They talked of, and sought remedies for, the crime which made them fear for their property, the drinking which made their workers unfit for productive labour, the supposed promiscuity and debauchery which de-stabilized the family unit and which therefore made the worker more socially volatile, the decline in church attendance which withdrew the work-force from a suitable source of moral values and homiletic, the insolence which, when displayed in the High Street, made a mockery of the social hierarchy.

In the preceding decade, there had been a number of developments which made these practical problems of social management seem even more acute. The end of the Napoleonic Wars in 1815 removed that external threat to British society which was so useful in maintaining a sense of social solidarity. When the French no longer, as it were, unified British society from without, the cleavages based upon competing social interests showed up more sharply. Also, following upon the end of the Wars was demobilization and economic slump, both of which added pressure to the social system. The increased level of 'combination' and trade unionism seemed to present a problem to those who recognized emergent working-class consciousness as a serious political development.

At the same time the rapid growth of the large industrial cities had produced no adequate response from the traditional sources of moral authority; the churches, especially the Established Churches of England and Scotland, could not keep up with the demand of burgeoning urban parishes. Less and less provision was being made for the moral management of working-class people, with the result that the lower orders were widely felt to be slipping out of the accepted 
system of moral values. If measures could not be found to bring them back into the moral order, then the successful achievement of industrial society would indeed be at risk.

From the end of the eighteenth century, institutional remedies had been sought for these problems. A whole range of institutional forms was developed, from the straightforwardly coercive to the manipulative and the educational. They grew rapidly in cities hitherto lacking even rudimentary forms of policing and law-enforcement: ${ }^{27}$ societies for the suppression of begging, societies for the prosecution of felons, temperance societies, friendly societies, urban missions, municipal police forces, and, of course, schools. Sunday schools, sessional schools, industrial schools - all were responses to the practical problems of managing an industrializing society. Many of those individuals involved in the foundation of local Mechanics' Institutes also assisted the development of these other attempts at control.

We can regard this plethora of institutional forms as 'experiments in social control', each reflecting different theories and strategies. Over time, the differential effectiveness of these strategies has doubtless had much to do with the pattern of institutional change and development. But, at the time, the dominant strategy stressed internal moral control. Most of the new foundations attempted to achieve a transformation in the values of those who attended them; they were designed to effect a system of values which would form a base for behaviour most desired by leaders of industrializing society, and which would militate against disruptive behaviour. Hence, educational enterprises were particularly favoured.

In 1834 Professor James Pillans of Edinburgh University was asked by the House of Commons Select Commission on Education whether he 'consider[ed] that as a means of prevention [of crime], education stands pre-eminent?' Pillans thought it did: 'So much so, that I conceive a well-digested system of national education skilfully carried into execution, would in the course of a generation or two almost extirpate crime.'28 Education for the lower orders was thought of as useful in respect of practical problems élites had in making their society work. It was not thought of purely with regard to intellectual outcomes; those intellectual outcomes were incidental features of the educational institution on the way to a stated, hoped-for pattern of behaviour.

Schools for the lower orders were justified as instruments of socialization. The knowledge they imparted and the manner in which they imparted that knowledge were similarly justified in terms of 
their contribution to a specific job of socialization. The general feature of the behaviour of the working classes which most disturbed the leaders of industrializing society and which most clearly cried out for remedy was its alleged instability. Industrial society required a stability of routinized behaviour which was difficult to achieve. To tend a machine a man had to adapt himself to the requirements of efficient mechanical production. ${ }^{29}$ Drunkenness was a practical problem because it decreased the stability of productive behaviour: immorality and sensuality was a practical problem because it threatened that institution which was thought to stabilize the worker's values generally - the family. The decline of the authority of religion was a practical problem because, in the absence of a stable source of moral values, the worker might be swept away by any number of transient social and political movements. The advocates of schooling for the working classes of early nineteenth-century Britain always argued their case in terms of the hoped-for achievement of stable patterns of values and the resulting stable patterns of behaviour. Whether they were speaking about schools for working-class children or 'adults their advocacy always stressed normative and social stability as the desired outcome of, and justification for, the educational enterprise.

Educational programmes for the 'mechanic' and 'operative' were indicated by a number of inter-related control strategies elaborated from the 1820s onwards and attaining their greatest significance around $1840 .^{30}$ These, essentially 'liberalizing', strategies all attempted to build an alliance or a community of interest between the bourgeoisie and the upper section of the working classes, the emerging labour aristocracy. In contrast to crude attempts at coercion or suppression, liberalizing strategies involved policies of 'cultural aggression' which by bribe or indoctrination would ensure that the 'natural leaders' of the working classes identified with and affiliated to those above them rather than those below.

Sometimes the emphasis would be simply upon splitting the lower orders and preventing the growth of a common consciousness among them, a crude policy of divide and rule. Sometimes the dominant position of artisans within the working classes, and the extent to which other workers were influenced by them, was emphasized. In either case, the generation of interest in property and the implantation of bourgeois culture among 'mechanics' and 'artisans' was clearly indicated. Educational interventions were frequently explicitly linked to these policies: 
The poorer classes are at present set against the rich; they are taught by arrant scoundrels, who speak to their sufferings, that not only the upper classes but the middling classes are their natural enemies and oppressers. . . . 'Divide and conquer' was a maxim of old. . . Are we to allow the union of bad spirits of various kinds to take advantage of the disunion of the wealthy....[?] $]^{31}$

Mechanics, skilled operatives and artisans (that is, the 'targets' of the early Mechanics' Institutes) were, if not already an objectively defined labour aristocracy in the 1820 s, well on the way to becoming one. Their political development was uncertain. They could lead the working classes in violent confrontation with the industrial system; they could lead them in drunken apathy; or, they could come to set examples of acceptance and identification with the values of the industrial middle classes. In the $1820 \mathrm{~s}$ the most politic course to take with the mechanic class was a matter of intense debate. This class, unlike the 'labouring poor', was almost totally literate. ${ }^{32}$ What they read, not whether they should read, was already a topic of concern. Many industrial leaders feared that, in the absence of more wholesome food, the mechanic was serving himself a diet of Cobbett, Paine and pornography. ${ }^{33}$ The mechanic was possibly already dangerous politicized.

This background of practical problems explains the aims and curricula of the Mechanics' Institutes at their inception. Such an interpretation is, of course, in no way novel. It is standard to relate institutional innovations in the early nineteenth century predominantly to an interest in social control. It is always worth exploring whether educational innovation can be related to such an interest, as an admirable and extensive literature in the history of education demonstrates. With regard to our present context, Lawrence Stone has shown that social control was the 'most powerful argument behind extension of education around 1800', and Richard Johnson has claimed that 'control was the essence of the phenomenon' 34 There is absolutely nothing special about Mechanics' Institutes insofar as they manifest social control aspirations on the part of their founders. In an important sense, this is the point. Several very perceptive writers on the history of British education, including the above-mentioned, have failed to comment significantly on the Institute movement, while brilliantly demonstrating how social control interests informed other educational programmes of the period. Indeed, Stone seems to hint that quite separate, technological, factors must account for the rise of the Institutes. ${ }^{35}$ There seems to be a general difficulty amongst 
scholars in conceiving how actors might think that science could aid in controlling people. When the curriculum contains religious and ethical injunctions, a social control intent has been readily recognized. However, the presence of science, being 'an objective account of nature', must, it is thought, be otherwise explained. It is our purpose now to show how it was thought that science could control the mechanic and why it failed to do so.

\section{THE SOCIAL ORDER AND THE INTELLECTUAL ORDER}

The problems of social control which we have stressed were, of course, the perceptions of particular interest groups in British society. Other sectors of the nation's upper classes shared neither the interests nor the perceptions which indicated support for the Institutes, or indeed for educating the working classes at all. It may serve to highlight the relationships between social experience and values, on the one hand, and the putative role of knowledge, on the other, if we devote some attention to the views of representatives of such groups.

The publication of Brougham's Practical Observations in 1825 elicited a lively pamphlet literature on the desirability of diffusing knowledge to the lower orders. Perhaps the most cogent of the many anti-Brougham authors was the anonymous 'Country Gentleman' who in 1826 published his 77-page Consequences of a Scientific Education to the Working Classes of this Country. ${ }^{36}$ The outcome of the work of Brougham's Institutes, 'Country Gentleman' claimed, would be precisely the social upheaval which Brougham and his colleagues said they were attempting to avert. ${ }^{37}$

How could the groups represented by Brougham and 'Country Gentleman' maintain such different opinions about the effects of knowledge on behaviour? It is likely that the answer lies in the ways in which the two groups saw their society.

'Country Gentleman' likens the existing social order to a pyramid 'the most lasting of all buildings' - in which the working classes, being the 'base', support the 'superstructure' formed by their social superiors. ${ }^{38}$ The gradation between ranks is 'scarcely perceptible'; the rungs on the great chain of social being are spaced very finely. Social harmony reigns, due submission is observed, the 'regular coherence and gradual subordination' observed in nature is also to be observed in British society, now as in the past. ${ }^{39}$ This social order 
is related to a moral and intellectual order; indeed, the one is dependent upon the other. If they 'map onto' each other, the social order is stable; if, however, one is altered, the other will change correspondingly. There is, appropriate to each rank in the 'social pyramid', a form and degree of knowledge. If individuals are given the knowledge appropriate to those of a higher station, they will inevitably, 'human nature' being what it is, press upwards, thus disturbing the stability of the social edifice. Give everyone the same type of education and the result, to be avoided at all costs, is democracy. Therefore, our ancestors 'wisely confined the superior sort of education to birth and wealth . . . ; because, where either one or the other was clearly superior, education or talents would be less invidious, and less likely, by producing discontent, to disturb the well-being of the state.' $\mathbf{4 0}$ If, in fact, the existing social order is stable, then there is no justification for altering the distribution of knowledge in society, and every reason for keeping it as it is. If Brougham's prescriptions are right, either 'our ancestors' were wrong (which is unthinkable), or 'some change has taken place in society which has rendered such an innovation necessary to the welfare of the state. ${ }^{41}$

This, of course, is the crux of the matter. 'Country Gentleman', from his perspective, does not recognize any such fundamental change occurring in British society, whereas Brougham and the advocates of popular education take it almost as axiomatic that important change has occurred and that dealing with it is a pressing practical problem. 'Country Gentleman' does not see the social hierarchy as having a dynamic aspect; Brougham does. We should say that the one can't see what the other can't help but see.

It has been said, 'Country Gentleman' admits, that the processes of industrialization and urbanization have already irrevocably changed the configuration of British society, that the lines of control have already been blurred. But, from his country seat, the opponent of popular science dismisses 'the changes that wealth and commerce have made' as mere 'excrescences' on the side of the social pyramid, 'which do not very materially affect the edifice'. The danger is not in social change; that is essentially illusory. The danger is in plots like Brougham's:

A scientific education to the working classes of society would derange the base. This constitutes the danger; for any alteration there, will level the superstructure with the dust. $\mathbf{4 2}$ 
Where Brougham and the projectors of Mechanics' Institutes sought institutional remedies to the problem of a breakdown in social control, 'Country Gentleman' saw no such breakdown. The stability of society did not have to be reconstituted or assured; based on due subordination of ranks and recognized lines of authority, it was a fact. This difference in perception may well correspond simply to differences in social experience. Agrarian society was perhaps indeed relatively stable; certainly it was stable with reference to conditions in places like the Manchester and Glasgow of the 1820s and 1830s. Perhaps, indeed, in 'Country Gentleman's' village, control was achieved through shared, accepted and traditionally institutionalized sources of authority.

The relationships between the arguments for and against the Mechanics' Institutes and those relating to popular education in general become clear if one examines the general educational propaganda of the early nineteenth century which Brougham and his colleagues drew upon. Among the most influential of the pro-popular education writers cited by Brougham and others is John Foster (1770-1843), a Baptist minister and essayist whose Essay on the Evils of Popular Ignorance (1820) argued the Christian case for educating the lower orders of British society. ${ }^{4}$ Like Brougham, and unlike 'Country Gentleman', Foster regarded education as a remedy for social illness. Society had in fact fundamentally changed in character, the change was still in process, and authority relationships in society were being seriously disturbed. Since the nature of society had already come into question, there was no going back; rather, the remedy was, through educating the people, to provide them with satisfying answers to questions raised:

Times may have been when the great mass . . combined such a quietude with their ignorance, that they had no other than submissive feelings towards these superiors . . . ; when no question would ever occur to them why there should be so vast a difference of condition between beings of the same race; when no other proof was required of the just appointment of their lot . . . than their being actually in it; and when they did not presume, even in thought, to make any inferences from the fact of the immense disproportion of numbers and consequently physical strength between them and their superiors. But the times of this perfect, unquestioning, unmurmuring succumbency under the actual allotment, have passed away. . .44

Foster saw that the fabric of society had been rent and that the reconstitution of the social order was dependent upon the reconstitution of the moral and intellectual order. Indeed, the Christian advocacy of popular education in early nineteenth-century Britain 
amounts to little more than this argument, variously embroidered. Popular education was self-consciously an innovation, to be defended in terms of novel social disorders which the new moral order was to cure.

Those who, like 'Country Gentleman', argued that Mechanics' Institutes (and, in fact, all forms of popular education) would corrupt the social order were refuted by others who gave a vivid account of an already corrupted society:

We must accuse the progress of wealth, the increase and condensation of the population, the facilities of locomotion, the quick circulation of intelligence. We must accuse commerce, manufactures, steamboats, stage coaches, newspapers; these are the real cause of the change in the community. Let those who entertain a doubt upon this point compare the different parts of the same country; let them compare the manufacturing with the agricultural counties; let them compare the towns even of the same county with its villages; or let them compare a retired village, which had little intercourse beyond its nearest market, with a village on some high road; and they will soon perceive in what the difference of character really originates... We must refer, then, to the state of society as the cause of corruption if the minds of the people are corrupted. . .45

Where, in places with a traditional economy and social structure, there remained a 'a spirit content to go forward in the beaten path', among industrializing communities there was 'a leaven ... of discontent and restlessness'. 46

\section{IMPUTING THE CHARACTERISTICS OF THE MIND}

In the debate over the most desirable social distribution of knowledge, actors revealed a number of organizing assumptions and theories. One of these, as we have seen, was that there had to exist an isomorphism between the social and the intellectual, cognitive order if society was to be stable. Another was that knowledge, if it were to be successfully transmitted, must be 'appropriate' to circumstances of its recipients. ${ }^{47}$ It must therefore be tailored to their environment (and thus their social standing), and to their nature, or what we today would call their intellectual capacities. It is particularly interesting to examine the way in which informal theories of the mentality of the lower orders thereby came to influence proposals for curricula in the field of popular education. To do this we must first set out 
what these theories were.

Central to the construction of a map of the lower orders' mind was the notion of hierarchy. Both projectors and opponents of popular education accepted that there was a social hierarchy, however much they differed as to its details, future and present stability. They also both accepted that the superior sort of person was endowed with or characterized by a superior sort of knowledge, and, conversely, that the knowledge of the lower orders was in important ways defective. They shared this fundamental belief whether or not they shared a belief in the desirability or possibility of improving the minds of the lower orders through education. A number of polar oppositions were generally used to contrast thought at the base and summit of the hierarchy and to characterize the lower orders as 'stupid'. The multitude's thinking was 'superficial' rather than 'profound;' it was based upon sense data rather than abstract organizing principles, and was accordingly 'sensual', not 'rational;' it was 'inconsequential', unlike the thought of the higher orders which took proper account of the consequences of action; it was 'fragmented', and failed to perceive those necessary connections between phenomena which gave the upper classes their integrated overall understanding of society and natural reality. 48

These oppositions may all be found in the already cited polemical literature dealing with Mechanics' Institutes and popular education in general during the early nineteenth century. The equation between the 'superficiality' of the working-class mind and the defective nature of their thought is clear in 'Country Gentleman's' statement that 'The populace ever judge superficially; the probability therefore is that they are ever wrong. . . 49 'Truth', he explained, 'is said to lie at the bottom of a well, not on the surface: in other words, whatever appears only superficially right, is probably wrong. ${ }^{50}$ Reality, therefore, lies deep; access to it requires the going behind of appearances, whereas the imputed characteristic of the lower-class mind is precisely its entrapment in appearances. Similarly, 'Country Gentleman' was totally convinced that the lower orders' characteristic relish for 'sensual and vulgar gratifications' could never be overcome by an induced 'love of learning'. ${ }^{51}$ Sensual gratifications were 'appropriate' to minds governed by sense, because they could not discern enduring moral verities lying deep beneath superficial sensual distortion. Even the virtues of mechanics could be turned against them with this idiom. 'It may be easily shown', claimed 'Country Gentleman', 
that practice and theory seldom unite in the same individual; that the occupation of the practitioner requires all his time and thoughts to fulfil the wishes of his eye or hand: whilst the theorist reasons within himself, and throws bimself on bis mind. Theoretical excellence must have reason for its soil, which mechanics have not. 52

The interior abode of 'reason', contrasted with the exterior quality of 'sensual apprehension', therefore mapped onto the social hierarchy. The lower orders were characterized, morally and intellectually, as having little notion of things except in 'external practice'. They lacked 'that busy interior existence, which is the moral person'. They did not apprehend 'ideas of what they cannot or dare not practically realize'.53 The daily occupations of the working classes made few, if any, demands upon the interior intellect; their minds resided in their eyes and hands, and were, therefore, susceptible of being unthinkingly routinized:

[We may] take into account of the allotment of employments to the uncultivated multitude, how much facility is acquired by habit, how much use there is of instrumental mechanism (the grand exempter from the responsibility that would lie on the mind), and how merely general and very slight an attention is exacted, in the ordinary course of some of the occupations. 54

As well as being shallow and sensual, the thought of the lower orders was inconsequential; it lacked purpose; it was insensitive to 'what things really mean'. 'One of the most obvious circumstances [of the 'ignorant class]', Foster wrote, 'is the perfect non-existence in their minds of any notion or question what their life is for, taken as a whole'. Their heads are full 'of trifling and corrupting ideas', but they never think: 'For what purpose am I alive? What is it that I should be? Does it signify what I may be?' Their thought lacks a 'general and leading purpose'. 55

Perhaps the central opposition underlying all these various imputations is that between 'organized' and 'fragmented' thought. We are offered a general characterization of the thought of the lower orders as 'broken-up', marked by transient and ephemeral impressions from the sensuous world and the passions, without the integrating cement of a patterned texture of meanings, necessary connections, causal laws, and the like. The contrast between the top and the bottom of society is made in terms of the distribution of what we may loosely call two opposed epistemologies.

There is little to suggest that this imputed distribution of 
epistemologies was made on the basis of concrete empirical study. It is more likely that it evolved as a legitimation of the social order; it justified the division of labour in society by accounting it 'natural'. However, once established as accepted wisdom, such a theory could be used to explain working-class behaviour, and to guide initial attempts to control it.

Thus, by characterizing the thought of the lower orders as fragmented and governed by transient impressions, their perceived immorality, insolence, sensuality and political volatility could be 'explained'. As they grasped no abstract moral and intellectual principles, they were at the mercy of whatever passing desire, whim or fancy arose from within or was impressed on them from without. Since they had no stable moral and intellectual framework with which to evaluate actions, any political rabble-rouser could simply sweep them along (see note 85, below). Bad influences simply impressed themselves upon their minds. Good influences would presumably impress themselves equally easily, but were distressingly uncommon in their environment.

For those who found the social control of the multitude problematic, this account of their mental characteristics also indicated a remedy. An educational regimen was required which took into account the nature of the minds with which it was going to deal, and which sought to instill in those minds the stable intellectual and moral patterns which it was felt they presently lacked.

\section{THE CURRICULUM}

We are now in a position to consider the curriculum which the Mechanics' Institutes were expected by their founders to sustain. Its intended nature is easily ascertained, although exactly how successfully it was embedded in teaching activity is more problematic. ${ }^{56}$ To summarize: the curriculum was to be scientific; 'pure' rather than 'applied'; factual rather than theoretical or speculative; and 'simplified' in presentation.

In the early curricula of most of the Institutes for which we have evidence, the natural sciences predominated. Although few Institutes continued to steer so close to their originally charted scientific course as the Edinburgh School of Arts, that enterprise was widely cited as the purest expression of the original ideas and its curriculum was copied by a number of other Institutes. ${ }^{57}$ The plan of the School, 
as designed by Brougham's friend Leonard Horner, was to teach chemistry and mechanical philosophy. Mathematics was soon added but other, seemingly more 'practical', offerings like veterinary medicine were resisted by the Directors as being outwith their purpose. 58 The central position in the curriculum of physics, chemistry, mathematics, the earth and life sciences (impressionistically arranged in order of importance) characterized the great majority of Institutes in their very early years. By the late 1820 s and early 1830 s very many, perhaps most, had presented lecture courses on phrenology, as a science of mind and philosophical system. ${ }^{59}$ The general tendency during the 1830 s was for the proportion of courses in the natural sciences to be diluted, usually by the addition or substitution of the fine and performing arts, languages, drawing, and the like. But this shift in the content of the curriculum corresponds to a previously-mentioned shift in the Institutes' purposes and clientele, and will not be discussed here. ${ }^{60}$

In itself, an elementary science-based curriculum concentrating upon the presentation and demonstration of clear-cut facts and laws may serve a variety of functions and interests. Those which are most relevant in the present instance are, however, readily discernible. Those features of knowledge which exposed its theoretical and conjectural qualities, and hence weakened its credibility, were systematically eliminated. So were those which facilitated original speculative thinking (despite utilitarian rhetoric upon the value of the innovating mechanic). What was retained was all that might implant a subtle model of natural order in such minds as the lower orders were thought to possess.

The knowledge of nature in which the intelligentsia orientated themselves was not to be the knowledge of nature presented to the mechanics. As the Rev Thomas Chalmers put it, by analogy with missionary work, it had been found more expedient to 'let down English knowledge and philosophy to the capacity and station of the Hindoos' than to attempt to 'raise the Hindoos to the level of English knowledge and philosophy'. 61 Brougham argued that, in teaching the 'multitude' geometry,

it is not necessary to go through the whole steps of that beautiful system, by which the most general and remote truths are connected with the few simple definitions and axioms; enough will be accomplished, if they are made to perceive the nature of geometrical investigation, and learn the leading properties of figure. 62 
The facticity of knowledge was to be emphasized at the expense of its metaphysical and hypothetical character. Thus, an organ of the Church of Scotland approved of the Edinburgh School of Arts' curriculum and teaching, but condemned the idea of workers spending their time

in puzzling [their] brains in algebra . . , or in wandering in the thorny path of metaphysics, or in the ill-macadamized roads of even physics themselves, where the lecturers ... . stand waving their rods over kittle curves and conic sections, and statements of the differential calculus, rather than in showing by experiment how things really are in nature . . 63

The central notion, shared by very many of the projectors of Mechanics' Institutes, was precisely this: to show 'how things really are in nature', rather than to stress, or in some cases even to allude to, the provisional nature of scientific knowledge. The world of workers' science was a world of facts and laws, not a world of theories so identified. Where Brougham or Horner might orientate themselves in a body of scientific knowledge which was partly hypothetical, wholly provisional, and recognized as theoretically informed, the scientific knowledge presented to mechanics was to have none of those characteristics. It was hard, factual, solid and enduring; in no way tentative or revisible. 64

Even mathematics was subject to audience-dependent adaptation of this sort. The Scottish educationalist and natural theologian Thomas Dick referred to the 'scientific method of instruction generally pursued in colleges and academies', wherein the student worked through Euclid and 'the higher algebraic equations', his attention being 'chiefly directed to the demonstration of mathematical propositions, without being much exercized in practical calculations'. But 'a different method ought to be pursued in schools chiefly devoted to popular instruction'. Let the student concentrate upon 'practical geometry', only occasionally exhibiting some of the abstract rules, 'in so far as he is able to comprehend it'. Practical operations of geometry and their 'general utility' will enable the student in such schools to comprehend the subject more than 'were he to consider them as relating merely to abstract trutbs',65 Another Scottish educationalist, James Pillans, claimed that in failed popular educational establishments the prime reason for lack of success was teaching which was 'too abstruse', which contained 'too much abstraction' 66

The science intended for the lower orders was a highly reified body of knowledge. And, by appeal to the observable and the concrete, 
it affected to be indubitable. Thus, in the Edinburgh School of Arts great weight was put upon actual demonstrations, concrete observable illustrations of 'how things really are', which were argued to be uniquely adapted to teaching the lower-class mind. Actual things which could be seen and handled were preferred subjects of study machines, chemical substances, geometrical diagrams; not algebraic variables and equations, metaphysical principles and unexemplified verbally expressed relationships. 67

The immense popularity of phrenology as an element in workers' education in the $1830 \mathrm{~s}$ is a prime example of reified knowledge as fit meat for the lower orders. In phrenology, as contrasted with academic mental science, abstract faculties become 'things', that is, parts of the brain. An observable entity is substituted for an abstract entity. Society is reified as the outcome of the workings of parts of individuals' brains. 68

Recalling our actors' model of the lower orders' mentality, one can recognize that this reified curriculum was intended to 'put into their heads', in the most efficient and most 'appropriate' way, an authoritative depiction of the natural world - of 'how nature was'. All that remains is to enquire why such an insertion was attempted. What was such a representation expected to do, once it had reached its target? How could it alleviate the problems involved in the social control of the lower orders?

Certainly, part of the answer lies in treating the science of the Institutes' curriculum as a control ideology analogous to earlier variants of natural theology and political economy. Models of nature are among the universally available resources invoked to set limits on the possibilities of human action. In particular, where people refuse to recognize the inscrutable whims and fancies of God as moral constraints, the more tangible, impersonal limits allegedly inherent in the operation of the natural world are likely to be invoked instead.

Such conceptions are, of course, readily discernible at this time in 'what people actually said' about the purposes of popular education. Again, John Foster is perhaps the most interesting link between the Institute movement and popular education in general in the 1820s. In his Essay on the Evils of Popular Ignorance he describes the relationship between the mental characteristics of the lower orders and the problems of bringing credible sanctions to bear on their behaviour. The lower orders, we remember, are blind to abstract principles, and, therefore, the notion of God as an abstract entity has but slight power to restrain the inclinations to $\sin$, or to impress the sense of guilt 
after it is committed'. Such a God lacks efficacy as a moral sanction 'because he is invisible'. ${ }^{69}$ As the lower orders are, however, sensitive to the tangible and the concrete, they usually do obey limits like walls and fences. The great problem is to make them aware of, almost literally 'to see', abstract intangible limits and moral principles which 'we' recognize. Thus:

as [the ignorant worker] is nearly destitute of that faculty of the soul which would perceive ... the awful interceptive lines of that other arrangement which he is in the midst of as a subject of the laws of God, we see with what insensibility he can pass through those prohibitory significations of the Almighty will, which are to devout men as lines streaming with an infinitely more formidable than material fire. ${ }^{70}$

The Church, with its abstract God, 'who is somewhere in the sky, has not, to them, the smallest force of intimidation from evil'. New sources of moral sanctions must be developed. In the distant past of our race, Foster believes,

some right injunctions of morality ... [were] infixed in the popular mind as a matter of conscience, by the great array of things pretendedly divine and demi-divine which surrounded, and pressed closely and powerfully on, the mind of the multitude. Whereas now, when this great array is vanished, there is nothing, absolutely nothing, to enforce moral principles and rules on the ignorant portion of the people with the mighty authority of Divine sanction. ${ }^{71}$

Although Foster did not fully articulate the solution, those who read his work did. The solution was in part to use a new 'divine' or 'demidivine' nature to exert those moral sanctions required to control an unstable multitude - a 'demi-divine' nature which was, appropriately, tangible and observable.

That 'demi-divine' nature was the construction of the natural theological science of late eighteenth- and early nineteenth-century Britain. The study of nature through science revealed moral purpose and significance in the world which could be encoded as ethical principles appropriate for oneself or others. Explicitly, the study of nature was recommended to mechanics as it revealed the wisdom of God in creating things as they were. 'Knowledge', said one popular scientific lecturer, 'is virtue':

All nature ... offers examples innumerable of the power and wisdom with which [God] works throughout the visible world before us. ${ }^{72}$ 
Nature was God's creation; it was His visible message and the respository of His plan. Nature was therefore a good nature, and if it appeared to be evil or unjust, there was God's beneficent purpose behind what appeared to be evil, such as the existence of the social hierarchy. The moral lesson to be learnt via the inculcation of natural theological science was one of acceptance, of appreciating the systematic connections which made a seemingly unaccountable world accountable in moral terms.

Interestingly, this natural theological knowledge was much more frequently encountered in the Institutes than political economy, which drew analogous conclusions from 'the scientific study of natural laws', and which might have been expected to have greater appeal to Whigs and reformers. Political economy and its 'iron laws' were indeed frequently explicitly excluded from Institutes' curricula, whereas the natural theological flavour of many courses, particularly in physiology, phrenology and, to an extent, the earth sciences is readily apparent. The phrenologist-educationalist George Combe, for example, was a strenuous advocate of the teaching of physiology to the common people. In a pamphlet on the subject he proposed a model catechism which opened with the physiology of digestion and concluded with the following exchange:

Q. If God has established all this in the framework of our bodies and the endowment of our minds, is he a clever fellow who tries to find a shorter way than by skilful and honest labour, to a supply of bread, who, for example, cheats to get it, or steals it? 'No, Sir.' ... Q. If, then, by working skilfully and honestly each of us in our own line, and exchanging our articles, we are all better supplied, and if God has arranged things in this manner, what kind of conduct does He prescribe to us, and approve of? 73

God is the ultimate source of moral suasion but now He acts through nature and natural laws. In the case above, diligent, honest and specialized labour is sanctioned by the laws of physiology, which God frames and guarantees. It is nature and the action of natural laws which exact their toll on those who violate 'natural' behaviour:

The whole objects and phenomena treated of in the sciences, are the institutions of God ... ; and ... we are bound by duty to God, as well by a regard to our own welfare, reverently and diligently to study these, and to regulate our own conduct in conformity to their modes of action.74

It is not an abstract God that will strike us down if we violate a code of behaviour; it is nature. Disease, degeneration, short life, mental 
afflictions await us if we drink to excess, are idle or sexually promiscuous. The body exacts its revenge on those who abuse it; the workings of the body are interpreted by science:

It is only by diligent study of the order of nature that we shall learn how to accommodate our conduct to the Divine laws, which regulate prosperity and adversity, health and disease, life and death, in the present state of existence. ${ }^{75}$.

It would, however, be misguided to treat the science of the Institutes simply and solely as a variant of natural theology, and we certainly do not advance this thesis. It was, after all, mathematics, mechanics and chemistry which initially were given pride of place in the curriculum, not physiology and phrenology. Without doubt one could draw teleological implications from mathematical and mechanical principles, but they are scarcely the most promising bases for an exercise in ideological ${ }^{\circ}$ manipulation. ${ }^{76}$ Nor is there any but the thinnest evidence that such principles were taught other than in a reasonably straightforward, if rather didactic, way. Few of the mathematical and physical texts employed came to include the passages of moralizing and homiletic characteristic of many works in other fields, and even of some of the physical science books written for use by children. 77

Why, then, was there such enthusiasm for the most apparently 'value-neutral' forms of science on the part of the founders and supporters of the early Institutes - people who, as we have seen, were predominantly interested in the defence of social order and stability? Why should science in general, and not just particular appropriate fields, be thought to possess a conrol function? ${ }^{78}$ And why should mathematics and mechanical philosophy be set above such apparently more promising sources of control as the biological and socio-economic sciences?

In answering such questions let us recall that a number of influential advocates did indeed urge the teaching of correctly-formulated political economy, usually of the Malthusian type. Certainly, Henry Brougham did so in his Practical Observations. ${ }^{79}$ And the Rev Thomas Chalmers argued at length that the Malthusian variant of political economy he favoured could be taught distinct from politics, and he encouraged its inclusion in Institutes' curricula. There was 'no likelier instrument than a judicious course of economical doctrine, for tranquilizing the popular mind'. It would be 'a sedative to all sorts of turbulence and disorder'. Moreover, it would be a splendid device for dividing the 
working classes: 'the infuriated operatives, instead of looking to capitalists as the cause of their distress, should look at one another' 80 But, in practice and in many locales, the intended introduction of such subjects aroused (or was thought likely to arouse) such passions among possible patrons that the enterprise was in jeopardy. And so there are matters of local institutional politics which clearly bear upon the content of the curriculum. ${ }^{81}$

Another possible answer has the virtue of setting the Mechanics' Institutes and their curricula in the more general context of educational innovation. They belong toward the end of a chain of cultural innovations leading from Paley on the one hand and Adam Smith on the other, through various strands of natural theology and political economy, always to increasingly naturalistic cosmologies. It is likely that what we have before us is a series of failed experiments in the construction of ideologies, all successively rejected by the lower orders, and successively replaced by apparently more objective and naturalistic alternatives. Perhaps élite groups continually found themselves obliged to curtail and tone down what ideally they would have wished to convey to the working classes, in a vain attempt to gain credibility.

What evidence there is strongly suggests that none of these ideological manifestations successfully distracted even a small proportion of the working classes from their own spontaneous political expressions. Only in the coercive context of schools for children did blatantly teleological interpretations of nature survive for any length of time, presumably being learned by rote and happily forgotten by successive captive audiences. ${ }^{82}$ There is nothing here to suggest that ideological manipulations, in themselves, entice people into alien cosmologies against their own interests. As Tyrrell has clearly and amusingly demonstrated, the would-be bringers of political economy enlightenment to the Scottish workers were regarded by their audience not as disinterested scholars but as 'employers' spokesmen sheltering behind a facade of religious, scientific and philanthropic notions'. One thousand Dunfermline working men subscribed to $\mathrm{Dr}$ Thomas Murray's political economy lectures in 1838, unfortunately for Murray as it turned out because the audience 'expected to hear the doctrines of Radicalism demonstrated'. And a Scottish judge, Sir Archibald Alison, in an attempt to cast doubt on the efficacy of popular scientific education as a means of social control, quoted this statement by the 'operatives of Manchester': 
We are anxiously looking for a new form of social organization, in harmony with the lights of the age, and Lord Brougham thinks to stop our mouths with kangaroos. 83

Given previous experience with recognizably ideological formulations, it may be that the curricula of the Mechanics' Institutes represent a modest, tempered and more realistic attempt at control. Their stress on mathematics and physical sciences reflects awareness that studied disinterest and apparent objectivity are essential if a suspicious audience is to be attracted and its credibility engaged $; \mathbf{8 4}$ this is the other side of the coin to the widespread ban upon political economy within the Institutes. And any lost opportunities for teleology and moralizing can be set against compensating advantages if only an audience of artisans can be held. By sacrificing time to mathematics and physics as 'loss-leaders', audiences for delicately-drawn implications of other sciences might be gained, and ongoing, informal contacts with the dominant sector of the lower orders established. Moreover, as we have noted already, 'value-neutral' science might crowd out even less desirable alternatives; artisans learning science are preferable to artisans plotting revolution; contemplative artisans are preferable to committed artisans. Analogously, in the world of the mind, valueneutral science 'occupies space' which the middle classes could fill with something else of their own choice. Thus, in terms of the characteristics they imputed to the minds of the lower orders, it at least is 'solid substance', producing a kind of stability and preventing that unpredictable tendency to be swept up by every kind of political stimulus characteristic of the utterly ignorant. ${ }^{85}$

We have obviously been treating the curriculum of the Mechanics' Institutes as a communication system, carrying messages of social control. But there are a variety of ways in which an educational situation may exert its hoped-for controlling influence, and only one of them, the content of the knowledge, is at the level of the explicit. Communication systems, and cultures generally, also carry with them a body of implicit meanings which can do important work in the social system. ${ }^{86}$ In the present context, we should also look to the general features of scientific discourse, the parameters of a scientific cosmology and the social messages conveyed by the very institutional existence of Mechanics' Institutes as important modes of communication and possible control; in other words, to the medium as well as the message.

We should recognize that the dissemination of science expanded 
a communication system and medium for discourse and interaction. It constructed channels along which an indefinite number of future attempts at negotiation and control could run. It provided a framework upon which the culture of a stabilized re-integrated society might eventually be built. And if this framework appeared permanent, immutable and constraining to the lower orders, but provisional, manipulable and challenging to those above them, so much the better; straight manipulation would be a pleasant bonus, but 'rational' communication, if that was all that could be achieved, was reward enough.

As usual, our actors themselves had explored the relationship between communication and control. Foster had deplored, and identified as very dangerous, the gulf of non-communication which had arisen between the higher and lower classes of the community, between 'refinement' and 'barbarism':

If so little of the sense, the information, the liberalized feeling, and the propriety of deportment, which we are to ascribe to the higher and cultivated portion, goes downward through the lower, it seems impossible but that there must be more of dissociation and repulsion between them, than of congruity and communication. But for the good of both it is exceedingly desirable that the upper and inferior orders should be on terms of communication ... and therefore that there should be a diminution of that rudeness of mind and habits which keeps them in such disconnexion and estrangement. 87

What was lacking was a 'medium of complacent communication', in the absence of which the lower orders were 'far removed and estranged from the more cultivated part of their fellow countrymen, and consequently from every beneficial influence under which a state of friendly contiguity, if we may so express it, would have placed them' 88 A member of the Glasgow Mechanics' Institute praised the role of such establishments in removing the feeling of jealousy and distrust, which has too long obtained between the higher and wealthier orders, and those in less favoured circumstances'. The image of scientific activity as essentially harmonious and co-operative could be invoked in the cause of control:

Meeting, as both classes do, on the fair field of science, where all are as brothers, and pursuing, it may be, the same glorious objects, the wall of separation is removed for ever, and the best possible guarantee given for the inviolable maintenance of the rights of property on the one hand, and the peace and security of society on the other. 89 
So long as significant numbers of 'mechanics' attended, the Institutes' directors rarely failed to remark on the decorous concord of classes at the lectures. How gratified the mechanics must be 'to have observed the very liberal manner in which your fellow-citizens, who occupy the higher stations of society, have come forward to assist you in obtaining that instruction which your own means alone could not command'.90 It was a cause of immense satisfaction to directors that middle and lower classes could make common cause in the pursuit of useful knowledge. As we have shown, our informal psychological theorists believed that manipulation at the cultural level would itself produce changes in society. Perhaps, if the cosmology underlying technological processes could be implanted in the operatives' minds, there would be more ready acceptance of the industrial system and their place in it.

It remains to ask why natural science in its more 'value-neutral' manifestations was selected as an appropriate medium of communication and potential common culture. Part of the answer doubtless lies in the lack of any realistic alternative candidates. And part must lie in the previous use of scientific culture for purposes of symbolic expression by industrially-based élites. ${ }^{91}$ But it is also possible that in some unverbalized, intuitive fashion, actors were aware of the way in which the concepts and procedures of science were particularly suited to expressing and exploring the many practical problems of organization and control they were experiencing as employers of labour and producers of commodities.

Here, indeed, we have arrived at a speculative and undocumentable hypothesis, but it is worth dwelling upon it for a brief moment before passing on. To treat matter instrumentally as the inert raw material required by a productive system organized to produce commodities requires that it be drained of moral significance and homogenized, precisely as occurs in the scientific thought of the élite. To explain and monitor systems of manufacture based upon organized sequences of single modifications of materials implies stochastically linkable, mechanistic notions of causality which are, again, characteristic of science. The control and co-ordination of complex, interdependent structures of organized productive labour is greatly facilitated in many ways by the institutionalized treatment of time as a linear continuum; many areas of science offer ideal models of such a treatment. And finally, and most importantly, modern commercial exchange and organized systematic production demand quantification and model procedures for dealing with quantified relationships, such 
as are again provided by the esoteric culture of natural science.

Thus, there may well have been a general, not necessarily explicit or conscious, realization that science was a particularly appropriate form of culture for general dissemination in an industrializing community. It could lay down in the mind the general form of a communication system appropriate for controlling and monitoring the current forms of production. Hence, it could help to establish the work habits required of a complexly organized work force, where individual components had to operate within close physical and temporal margins of error, and were highly interdependent and minimally redundant. 92

\section{THE MORAL FORCE OF NATURE}

We shall conclude by relating the foregoing discussion to the general question of how knowledge is connected with an interest in social order and control. It is the relevance of our material to aspects of this important, enduring problem which has, for us, been the main source of its significance.

Let us start with the problem of whether general systems of ideas, world-views or cosmologies, in themselves, can ever effectively control the behaviour of the audiences to which they are addressed. This is an important focus of controversy among historians and social scientists. In the Marxist tradition, an orthodox position which insists upon the derivative status of such ideas - of consciousness - is, for readily intelligible reasons, perpetually threatened by idealist heresies which proclaim the potency of ideologies and legitimations as autonomous determinants of men's actions; indeed, this idealist strand of Marxism has probably never been more influential than at the present time. Similarly, among those sociologists and anthropologists who loosely follow the work of Emile Durkheim, and who constitute the only other coherent sociological perspective upon knowledge and its production, the predominant conception of cosmologies as reflections or derivative analogues of the social order, exists in perpetual tension with its converse. 93

Thus, there are significant numbers of scholars who, like our innovating bourgeois groups, believe that knowledge can control people. On the whole, what we know of the Institutes counts against this belief. The cosmologies and bodies of knowledge first put forward in the Institutes were not effective in fufilling their intended task. 
The Institutes failed to create a viable audience from 'mechanics' and 'artisans', evidently proving much more attractive to 'petty-bourgeois' groups whose existence and behaviour were not regarded as problematic. They failed to modify the consciousness of the working classes to any significant degree. And their science did not become accepted among the lower orders as objective renderings of nature or neutral frameworks for discourse and communication. Hence their tendency to make way for curricula conceived in terms of other functions: entertainment, or, much later, the genuine transmission of utilizable technical and computational skills.

Certainly we regard the evidence in this case as tending to confirm our own preferred general view, that people cannot be controlled through ideas; that it is only through coercion, the manipulation of rights, or the generation of interests that social order can effectively be promoted or broken down. Such a general hypothesis, however, can never be straightforwardly established or refuted by passive comparison with any particular set of findings. What proportion of workers, or mechanics, came to accept the doctrines of the Institutes, in itself, settles nothing. Those who believe in the potency of ideology will, we surmise, be able to find reasons for its general inefficacy in this particular case, just as we, from our perspective, do not regard it as at all inexplicable that workers and artisans did, very occasionally, accept the cosmology of the Institutes.

Unfortunately, we know far too little about such men; further investigation of their numbers and background would be of great interest. $^{94}$ Nevertheless, given the general content, their existence in limited numbers, far from being an anomaly, is very much to be expected on our account. In the 1830 s and 40 s, a 'labour aristocracy' was differentiating as a consequence of economic change and industrialization, and a part of it was developing a characteristic 'respectable' culture and sustaining such institutions as Mutual Improvement societies, and the Temperance and Co-operative movements. $^{95}$ The immediate, expedient interests of this group did at times lead them to ally with those above rather than those below. And, as we have mentioned, employers and their associates sought to encourage their differentiation and their alliance. As well as cultural offerings like Mechanics' Institutes, they preferred financial incentives, increased access to rights in property, the hope, and to a very limited extent, the actuality of upward social mobility. To the very limited extent that they could be bought in this way, we would expect workers 
to be more receptive to bourgeois culture and cosmology; for those with hopes of upward mobility, or profiting from privileges guaranteed from above, this would not be an inappropriate form of cultural expression. To ascribe the behaviour and beliefs of such groups of workers to the potency of the Institutes' curricula would be to misread the consequences of economic change and the manipulation of interests as the consequences of ideas and ideologies.

Let us move now to the question of when, and under what circumstances, social groups resort to conceptions of nature as instruments in attempts at social control. The work of social anthropologists, involving the widest possible comparisons of the cosmologies of different societies, has revealed the significance and complexity of this question. In Purity and Danger (1966), Mary Douglas suggested that whether or not natural knowledge reflected an interest in social control was determined by the social structure of the society in question. In simple societies, lacking the social and institutional differentiation of modern industrial communities, social control is particularly problematic. Such societies lack that interdependence of parts which, in modern societies, makes for social stability and the encapsulation of conflict; nor have they evolved specialized institutions - police forces and social workers, courts of law, public files and records, and the like - to monitor and control deviance. The consequent greater degree of concern with social control as a practical problem leads to the invocation of nature as a guarantor of the moral order. Natural disaster is threatened as the consequence of wrongdoing; good crops or good hunting bless conformity. Thus, anthropomorphic accounts of nature 'crystallize in the institutions'; a morally-alive cosmology emerges over time. Conversely, in 'modern' societies moral and natural knowledge are free to differentiate apart from each other; forms of knowledge with impersonal cosmological implications can emerge; conceptions of nature need not be put to work in the interest of social order. Modern science is thus the characteristic, impersonal knowledge of a differentiated social structure; it is knowledge which has been able to develop unconstrained by an interest in social order and control and resultant anthropomorphizing tendencies.

In her later books, Natural Symbols (1970) and Implicit Meanings (1975), Professor Douglas repudiates this interesting thesis. Having become aware of the moral use of appeals to nature in modern societies, and of the existence of impersonal cosmologies in simple ones, she is limited to advancing a weaker hypothesis: where people 
value the existing social order and strong social controls, this will be reflected in their cosmologies and systems of symbols; where they do not, it will not. Since, in modern societies, an interest in social control and the maintenance of the existing order is always evident, at least in some groups, Professor Douglas consistently argues that we can never assume our own natural knowledge to be sustained independently of such an interest; indeed she suggests that a society wherein conceptions of nature were never invoked for moral or political ends is 'unimaginable'. Like the historical materialists, Professor Douglas now believes that social control remains problematic for ruling or exploiting groups in all existing societies, and knowledge is always liable to be influenced by this, and hence to reflect the distribution of power.

The point is a good one; certainly it would be foolishly complacent to assume the opposite; but it is surely still worthwhile to speculate, as Mary Douglas did in her earlier Purity and Danger, on what affects the extent to which knowledge is influenced by an interest in social control. The protagonists of our study projected the organization and modification of knowledge almost entirely in terms of an interest in control. Popular education generally, at the time, was overwhelmingly dominated by the same interest. The content of its knowledge, its idiom, its arrangement, its structure, in every context, at every level, clearly revealed the influence of that interest.

Correspondingly, our protagonists, compared to ourselves, were intensely concerned with the problem of social order: they feared revolution; they feared massive social breakdown. And, arguably, their fears reflected their position at a real point of comparative institutional instability. Going back in time, mentally reversing the processes of urbanization and industrialization, we regenerate a society more and more in the grip of traditional institutional forms. Going forward into the second half of the century, we find many of the control institutions inaugurated in the great sequence of bourgeois innovations taking effect, and the social relationships and conflicts in the urban areas stabilizing and moderating for other reasons.

Does this suggest that at times when problems of order are overstretching the resources of existing mechanisms of control, before institutional responses become operative, there is a heightened tendency to have recourse to conceptions of nature, and any other ideological sources of moral justification, in a (futile) attempt to control people directly by ideas? Or does this hypothesis merely reflect our own lack of correct awareness, the extent to which we 
are successfully gripped by current ideologies?

Finally, let us consider how knowledge is affected, when it is generated and developed under the stimulus of an interest in social control. In general, the effect is thought to be an adverse one, although how precisely it is conceived of varies. Realists would perhaps say that such an interest can serve only to distort belief out of correspondence with reality. Instrumentalists might argue that beliefs adapted to further social interests cannot be optimally designed to further an interest in prediction and technical control, which is what we expect our scientific knowledge to be. ${ }^{96}$ In Purity and Danger, Mary Douglas considers that an interest in social control anthropomorphizes knowledge and makes the universe morally alive; impersonal, objective knowledge only appears as the importance of this interest in its constitution declines. For Marxists generally, limited social interests of any kind are sources of ideological distortion.

All these positions indicate, quite rightly, a particular need for caution in according credibility to beliefs in any way connected with an interest in social control. But it is unfortunate that they are often taken to imply on the one hand that there is no need to take such beliefs seriously, and on the other that the development of our currently accepted science cannot possibly be connected in any way with an interest in control. Such views, when simply taken for granted as obvious truths, unduly restrict research and prevent proper consideration of what are, in the last analysis, matters to be decided via empirical investigation.

One plausible interpretation of our material is that it shows the operation of an interest in social control upon knowledge leading to greater impersonality and objectivity. As we have said, the ideological precursors of the Institutes' curricula were the crude teleological formulations of eighteenth-century natural theology, and the restricting 'iron laws' of the political economists which had nature guarantee the failure of any attempt to alter the basics of the economic order. In the early Institutes themselves, we find a movement away from these cosmologies toward increasingly objective, 'value-neutral' forms of knowledge: political economy was not infrequently taboo; mathematics and mechanics were generally given pride of place. We know that this was often done to facilitate cooperation among the higher orders, where opposed groups readily perceived the moral and political presuppositions of their opponents in their most favoured cosmologies. And we may reasonably surmise that this move was also intended to secure greater credibility among the lower orders, who, 
despite their allegedly fragmented and manipulable consciousness, were evidently as well able as their betters to sniff ideology and reject it. If this was so then our protagonists were being forced to propagate more and more 'value-neutral' cosmologies as they experimented with the problem of producing an adequate integrative ideology in a conflict-riven social structure.

We shall not attempt to work out what the implications of this suggestion would be with respect to the vast changes in the content and organization of institutionalized natural knowledge which followed our period. It is, however, worth suggesting that in differentiated societies, with a balance of power between conflicting yet interdependent groups, an interest in social order, rather than being a constraint upon the emergence of the kind of knowledge which we, today, tend to value and regard as justified, might assist its growth and the decline of alternative forms.

\section{NOTES}

We should like to acknowledge the helpful criticisms of an earlier draft of this paper offered by, among others, Roy Porter, Roger Cooter, J.B. Morrell, Madeleine MacDonald, John Law and an anonymous referee for this journal. An extended excerpt from this paper has already appeared in Schooling and Capitalism, edited by the Open University (London: Routledge and Kegan Paul, 1976), 55-65.

1. For an excellent 'contextual' approach to educational policy in general during this period, see Richard Johnson, 'Educational Policy and Social Control in Early Victorian England', Past and Present, No.49 (November 1970), 96-119. Some of the more important sources for the history of the Mechanics' Institutes include: Mable Tylecote, The Mechanics' Institutes of Lancashire and Yorkshire before 1851 (Manchester: Manchester University Press, 1957); Thomas Kelly, A History of Adult Education in Great Britain (Liverpool: Liverpool University Press, 2nd edn, 1970), Chapter 8; D.S.L. Cardwell, The Organization of Science in England (London: Heinemann, rev. edn, 1972), 39-44, 71-75; Harold Silver, The Concept of Popular Education (London: Macgibbon \& Kee, 1965), 210-26; J.F.C. Harrison, Learning and Living, 1790-1960 (London: Routledge and Kegan Paul, 1961), 57-89; Brian Simon, Studies in the History of Education, 1780-1870 (London: Lawrence \& Wishart, 1960), Chapters 3-5. Valuable on the later career 
of the movement is Edward Royle, 'Mechanics' Institutes and the Working Classes, 1840-1860', The Historical Journal, Vol. 14 (1971), 305-21. Ian Inkster, 'Science and the Mechanics' Institutes, 1820-1850 : The Case of Sheffield', Annals of Science, Vol. 32 (1975), 451-74, came to our attention after this paper was written and contains material we would otherwise have addressed ourselves to. In addition there is a continuing stream of MEd theses on various Institutes, and a body of superficial accounts typified by M.D. Stephens and G.W. Roderick, 'Science, the Working Classes and Mechanics' Institutes', Annals of Science, Vol. 29 (1972), 349-60.

2. There are a number of papers tracing the development of the Manchester Mechanics' Institution in D.S.L. Cardwell (ed.), Artisan to Graduate (Manchester: Manchester University Press, 1974).

3. Some writers credit George Birkbeck's popular courses at the Andersonian Institution, Glasgow (1800-1804); others point to the Edinburgh School of Arts (founded 1821), the Glasgow Mechanics' Institution (1823), or the London Mechanics' Institution (1823).

4. Full title: Practical Observations upon the Education of the People, addressed to the Working Classes and their Employers (London, 1825); all quotations from the 13 th edition. At least twenty editions were printed in 1825 alone. Brougham's arguments had been previewed earlier: [Brougham], 'Scientific Education of the People', Edinburgh Review, Vol. 41 (October 1824), 96-122.

5. For an earlier scheme, not successfully taken up, see Thomas Dick, 'Hints for the General Diffusion of Science. . . ', Monthly Magazine, Vol. 37 (1814), 219-21, 507-10; Vol. 38 (1814), 23-25, 121-22, 503-06.

6. J.N. Hays, Science and Brougham's Society', Annals of Science, Vol.20 (1964), 227-41; Elaine Anne Storella, 'O, What a World of Profit and Delight': The Society for the Diffusion of Useful Knowledge (unpublished PhD thesis, Brandeis University, 1969).

7. Sources for compiling lists of Institutes include the following: J.W. Hudson, The History of Adult Education (London, 1851), vi, 222-36 (the estimate above comes from vi); House of Commons, Report from the Select Committee on Public Libraries (1849), especially evidence of Samuel Smiles (306-09) and J.B. Langley (310-17); T.E. Cliffe-Leslie, An Inquiry into the Progress and Present Conditions of the Mechanics' Institutes (Dublin, 1852); James Hole, An Essay on the History and Management of Literary, Scientific, and Mechanics' Institutions (London, 1853).

8. See, for example, the map in Cardwell, op.cit. note 1, 75 .

9. Majority 'worker' representation on the Board of Directors, as urged by Brougham, did not, of course, necessarily mean 'worker-control'. We also know of cases where middle-class founders liked, for good reasons, to give the impression that the impetus for the Institute's establishment came from the workers themselves. Finally, it seems that the control and uplift rhetoric of the supposedly worker-controlled Glasgow Mechanics' Institution is little different from the bourgeois-controlled Edinburgh School of Arts (see below, esp. note 89).

10. For accounts of involvement of middle-class members of scientific societies in founding Institutes, see Steven Shapin, 'The Pottery Philosophical Society, 1819-1835: An Examination of the Cultural Uses of Provincial Science', Science Studies, Vol. 2 (1972), 311-36, and Arnold Thackray, 'Natural 
Knowledge in Cultural Context: The Manchester Model', American Historical Review, Vol. 79 (1974), 672-709 (esp. 701-02).

11. For a contemporary illustration of this, see [David Robinson], 'Brougham on the Education of the People', Blackwood's Edinburgh Magazine, Vol. 17 (1825), 534-51 (538). As we show below, there were important lumping generalizations about the lower orders as well as important distinctions.

12. E.g. Hudson, op.cit. note 7, vii, 130-31:

Within five years from the establishment of this [the Manchester Mechanics'] Institution it was observed that the few mechanics who adhered to the society were almost wholly composed of those workmen who had distinguished themselves for their skill and ingenuity, and that the new members were chiefly clerks and warehousemen, who sought, by the aid of the Mechanics' Institution, to cultivate a taste for liberal and useful knowledge. The sphere of the society's operations was therefore extended to a new class of persons.

Royle, op.cit. note 1 , cites the 1840 Report of the West Riding Union of Mechanics' Institutes:

... the members of the mechanics' institutes are, nineteen-twentieths of them, not of the class of mechanics, but are connected with the higher branches of handicraft trades, or are clerks in offices, and in many instances young men connected with liberal professions.

We should also note the widespread introduction of ladies to the Institutes' audiences during the 1830 s. Tylecote, op.cit. note 1,297 , provides a membership chart of the Manchester Institution, but unfortunately it only commences with the year 1835 - eleven years after its foundation. Preliminary analysis of the audience for the Edinburgh School of Arts by one of us (S.S.) confirms a marked increase in the proportion of clerks and shopkeepers from 1821 to the late 1830 s.

13. Andrew Thomson, quoted in The Scotsman ( 8 June 1825). Dichotomies between sensual and intellectual modes of apprehension fit easily into the nomenclature of phrenology. See, for example, George Combe, Lectures on Popular Education (Edinburgh, 3rd edn, 1848), 25 :

Life with [the industrious classes] is spent to so great an extent in labour, that their moral and intellectual powers are stinted of exercise and gratification: and hence their mental enjoyments are chiefly those afforded by the animal propensities: in other words, their existence is too little rational; they are organised machines more than moral, religious and intellectual beings.

14. Thomson, op.cit. note 13.

15. Quoted in Shapin, op.cit. note 10, 333.

16. Ibid., 332.

17. Leonard Horner, in First Report of the Directors of the School of Arts of Edinbugh (Edinburgh, 1822), 15. 
18. Thomas Chalmers, 'On Mechanic Schools ... ', The Christian and Civic Economy of Large Towns, III (Glasgow, 1826), 378-79.

19. Of course, many popular educationalists advocated a largely non-scientific curriculum, feeling that stiff doses of religion and traditional moral preaching would do an effective job of control. Thomas Dick presents an interesting example of an early advocate of popular education who later criticized Mechanics' Institutes for not making it sufficiently clear that moral and religious lessons were to be drawn from natural knowledge. See Dick, On the Mental Illumination and Moral Improvement of Mankind (Glasgow, 1835), 581-600.

20. See the splendid study by R.K. Webb, The British Working Class Reader, 1790-1848: Literacy and Social Tension (London: George Allen \& Unwin, 1955); also R.D. Altick, The English Common Reader: A Social History of the Mass Reading Public, 1800-1900 (Chicago: University of Chicago Press, 1957).

21. The Scotsman (7 September 1822). A Whig Director of the Edinburgh School of Arts stressed this point:

The Tories of Edinburgh are too sharp-sighted to be misled ... ; but they, too, saw clearly that, while they would gain in character, they could lose nothing politically by supporting this School of Science, . . . In no respect, certainly, was it likely to be more useful, than by affording an opportunity for men of all parties - men too often incensed against each other on account of political struggles and differences - to meet together, and unite cordially in prosecuting a common object, which should, at the same time, secure to them all the respect and better affections of other classes in society. (Ibid.)

22. It is interesting that workers' self-education enterprises set up in opposition to middle-class controlled Institutes often made a point of including novels, newspapers and political literature. See, for example, details of the Edinburgh Mechanics' Subscription Library, The Scotsman (16 April 1825). Also R.G. Kirby, 'An Early Experiment in Workers' Self-Education: the Manchester New Mechanics' Institution, 1829-35', in Cardwell (ed.), op.cit. note 2, 87-98 (esp. 92-93).

23. There was also an important 'rhetoric of utility' associated with the founding of many Institutes. However, taking at face value the utilitarian justifications made for Institutes leads to serious problems of interpretation. Such an assertion may sound forced, especially to those familiar with the careers of those very few Institutes which were transformed into technical colleges later in the century (e.g. the Manchester Mechanics' Institution and the Edinburgh School of Arts). But the initial stress of the Institutes on 'pure' science and 'scientific principles', their general neglect of applied subjects and practically relevant knowledge, and their total failure to develop (or even seriously to plan for) actual technical research, does cast doubt on the extent and immediacy of genuine utilitarian concerns as motivating their foundation. Moreover, the claim that teaching 'principles' created more creative and innovative employees comes oddly from those who, at the time, were obsessed with inculcating in their labour-force a rigid conformity and docile acceptance of routine. We shall 
see later that the Institutes' curricula included a reified, atomized, anti-theoretical version of scientific knowledge designed precisely to constrain its recipients and stultify their imagination. As for the general avoidance of clearly useful knowledge, this was probably essential at a time when employers and employees alike found it in their interests to prevent its dissemination, in order to exploit its possession by themselves.

Moreover, we now have a very detailed study of a major Mechanics' Institute in a very different social context which provides indirect support for our interpretation. Bruce Sinclair's history of the Franklin Institute (see note 52, below) is an account of a popular scientific organization founded in Philadelphia in 1824, and largely inspired by British models. What is striking in his account is that the Franklin Institute rapidly 'makes good' the traditional utilitarian justification for scientifically educating the people. It soon is undertaking largescale technical research activities which are perceived as useful by American manufacturers and politicians. There is no evidence whatsoever in Sinclair's account that problems of social control were of immediate significance to contemporary Philadelphians, or that the Institute was motivated by a desire to remedy social disorder. On the other hand, in the British urban context where social control was a practical problem, not one Mechanics' Institute of which we are aware undertook, in its early career, to translate its utilitarian rhetoric into applied research reality.

24. John Foster, Class Struggle and the Industrial Revolution: Early Industrial Capitalism in Three English Towns (London: Weidenfeld and Nicolson, 1974), is the best, and most provocative, recent source on this.

25. See the superb essay by Sidney Pollard, 'Factory Discipline in the Industrial Revolution', Economic History Review, 2nd series, Vol. 16 (1963-64), 254-71: also Michael Sanderson, 'Education and the Factory in Industrial Lancashire', ibid., Vol. 20 (1967), 266-79.

26. Brian Harrison, Drink and the Victorians (London: Faber and Faber, 1971 ) is an excellent treatment of the Temperance Movement and its social purposes.

27. This was the period during which organized municipal police forces came into being. Parliamentary commissions on the policing of cities were as numerous as those on the education of the lower orders.

28. House of Commons, Report from Select Committee on the State of Education (London, 1834), 49. For similar sentiments, see Dick, op.cit. note 19, 526-41.

29. Pollard, op.cit. note 25,258 , quotes Arkwright's complaint that it was proving difficult to train 'human beings to renounce their desultory habits of work, and identify themselves with the unvarying regularity of the complex automaton'. Andrew Ure, The Philosophy of Manufactures (London, 1835), is a fertile source of such locutions.

30. This thesis is advanced and established, with particular reference to Oldham, by Foster, op.cit. note 24 .

31. Address to the Inhabitants of Edinburgh on the Necessity of Removing the Causes of the Crimes which now Disgrace the City (Edinburgh, 1832), 6-7, 12 .

32. Lawrence Stone, 'Literacy and Education in England, 1640-1900', Past and Present, No. 42 (February 1969), 69-139 (110).

33. On this point, see Johnson, op.cit. note 1, 106; Webb, op.cit. note 20, 
passim.; Stone, op.cit. note 32, 85-86. For a contemporary perception, see Robinson, op.cit. note 11, 542:

. . . the 'people', when they are embarked in party-politics, will ever turn in contempt from Brougham and Place, to read Cobbett and Carlisle.

34. Stone, op.cit. note 32,91 ; Johnson, op.cit. note $1,119$.

35. Stone, op.cit. note $32,137$.

36. Full title: The Consequences of a Scientific Education to the Working Classes of this Country pointed out; and the Theories of Mr. Brougham on that Subject Confuted; in a Letter to the Marquess of Lansdown. By a Country Gentleman (London, 1826). Other pamphlets in the controversy include: Henry Martin, Observations on the Importance and Advantages of the Education of the People (London, 1826); E.W. Grinfield, A Reply to Mr. Brougham's 'Practical Observations upon the Education of the People....' (London, 1825); George Wright, Mischiefs Exposed. A Letter addressed to H. Brougham, Esq., M.P. shewing the Inutility, Absurdity and Impolicy of the Scheme Developed in his 'Practical Observations ... ' (London, 1826).

37. As 'Country Gentleman' put it :

[Brougham] cannot surely be so blind to his own interest, as to promote so alarming an alteration. (Op.cit. note $36,53$. )

38. Ibid., 4-6, 16.

39. 'Country Gentleman' found Pope's celebration of the eighteenth-century Great Chain of Being entirely apt as a description of British society in 1825 . (Ibid., 8)

40. Ibid., 9 .

41. Ibid.

42. Ibid., 16.

43. Full title: An Essay on the Evils of Popular Ignorance: and a Discourse on the Communication of Christianity to the People of Hindoostan (London, 2nd edn, 1821). There were at least five editions of Foster's book.

44. Ibid., 205-06.

45. [John Bird Sumner and J.T. Coleridge], 'Mechanics Institutes and Infant Schools', Quarterly Review, Vol. 32 (1825), 410-28 (415-16).

46. Ibid., 416.

47. Brougham (1825), op.cit. note 4,9 .

48. This model of thought has been widely and persistently applied. Similar characteristics have repeatedly been discerned in the thought of other races, preliterate communities, mental defectives and children. It would be interesting to explore how far recent scientific work, such as that of A. Jensen (Genetics and Education [London: Methuen, 1972]) should be taken as a further example of this. Presumably, the model serves as a general rationalizing resource which accounts those operating on the basis of an alternative scheme of things as having 'no scheme of things', and those with alternative conventions of rationality as 'irrational'.

49. 'Country Gentleman', op.cit. note 36, 66. 
50. Ibid., 17-18.

51. Ibid., 22. A key difference between educational reactionaries like 'Country Gentleman' and reformers like Foster and George Combe is that the former believe that the imputed mental characteristics of the lower orders are 'natural' (therefore, not surmountable), while the latter hold them to be 'induced by society' (hence, 'unnatural' and improvable by social intervention). See, for example, Combe, op.cit. note 13 : Combe maintained that it was a violation of natural law not to exercize all the mental faculties - rational as well as animal. For an analysis of the rhetorical resources employed to express these mental models, see S. Shapin and B. Barnes, 'Head and Hand: Rhetorical Resources in British Pedagogical Writing, 1770-1850', Oxford Review of Education, Vol. 2 (1976), in press.

52. Ibid., $51 \mathrm{n}$; italics in text. Even in the Franklin Institute of Philadelphia, educational planners observed that 'To practical men, theoretical discussions are, in general, unintelligible'. (Bruce Sinclair, Philadelphia's Philosopher Mechanics: A History of the Franklin Institute, 1824-1865 [Baltimore: Johns Hopkins University Press, 1974] , 197.)

53. Foster, op.cit. note 43, 163-64.

54. Ibid., 169-70.

55. Ibid., 133-34; italics in text.

56. One great problem in writing the history of Mechanics' Institutes is that there is so little evidence as to precisely how science subjects were taught in the various establishments. Even in the case of the larger Institutes, such as the Edinburgh School of Arts, only a few teaching texts survive; there is very little anecdotal information from teachers as to their pedagogical methods, and almost none whatsoever from students as to their experiences of being taught. Existing sources reveal that, with very few exceptions, the lectorial style was universal. Examination, and the awarding of diplomas, was confined to the most ambitious Institutes in the largest cities. This scarcity of evidence on pedagogy makes it impossible for us to address ourselves to the very interesting suggestions relating knowledge to control in Basil Bernstein, Class, Codes and Control (London: Routledge and Kegan Paul, 1971).

57. The Scotsman (1 January 1825):

... Unlike some of the mechanic institutions which have been established in other places, after the example of the Scbool of Arts, but which have wandered widely from the model, the students here have their attention solely directed to those objects which will be of real practical utility to them in their trade.

The Edinburgh model was followed by the founders of the Manchester Mechanics' Institution, including the resistance to artisan-representation on the Directorate. (Tylecote, op.cit. note 1, 129-31.)

58. Mathematics was soon added because it was found difficult in practice to teach physics to students with inadequate numeracy. The Directors reluctantly accepted an offer of gratis lectures on farriery and architecture, while consistently resisting the teaching of 'a great many branches of science, which would distract [the student's] attention by their multiplicity . . . without increasing [the] utility [of the School].' (Leonard Horner, The Scotsman [2 June 1824].) 
59. David de Giustino, Conquest of Mind: Phrenology and Victorian Social Thought (London: Croom Helm, 1975), Chapter 8; Terry Parssinen, 'Popular Science and Society: The Phrenology Movement in Early Victorian Britain', Journal of Social History, Vol. 8 (1974), 1-20. For a phrenologically-informed programme for a Mechanics' Institute, see Sir G.S. Mackenzie, General Observations on the Principles of Education: for the Use of Mechanics' Institutions (Edinburgh, 1836), an address delivered to the Inverness Mechanics' Institute.

60. Cf. Royle, op.cit. note 1 ; Tylecote, op.cit. note 1, 133, 139.

61. Thomas Hanna, Memoirs of the Life and Writings of Thomas Chalmers, D.D. LL.D., III (Edinburgh 1851), 26; The Scotsman (2 June 1824); Third Report of the Edinburgh School of Arts (Edinburgh, 1824), 4-8.

62. Brougham, 1825 , op.cit. note 4,9 .

63. 'On the General Question whether the Labouring Classes Ought to be Educated, and to what Extent', The Edinburgh Christian Instructor, n.s., Vol.2 (1833), 519-27 (519-20); italics in text.

64. Compare this with the allegedly 'metaphysical science' of the Scottish academic tradition (G.E. Davie, The Democratic Intellect: Scotland and Her Universities in the Nineteenth Century [Edinburgh: Edinburgh University Press, 2nd edn, 1964], Chapter 8.). Although the strong form of Davie's thesis remains in some doubt, there is a real contrast in the 'philosophical' character of the two forms of education.

65. Dick, op.cit. note $19,386-87$; italics in text.

66. James Pillans, Three Lectures on the Proper Objects and Methods of Education in Reference to the Different Orders of Society . . (Edinburgh, 1836), 19-20.

67. For example, Combe on popular physiology:

The use of function is far better understood when founded on a demonstration of the structure than when communicated merely by verbal description ... (George Combe, On Teaching Physiology and Its Application in Common Schools [Edinburgh, 1857], 3.)

The point is not that 'demonstrations' are only to be found in the teaching of the working classes, but that they are stressed when the students are regarded as deficient in the abstract thought required; workers were regarded as constitutively deficient. Cf. Shapin and Barnes, op.cit. note 51 .

68. Some suggestions as to the sociological basis of the two epistemologies are contained in Steven Shapin, 'Phrenological Knowledge and the Social Structure of Early Nineteenth-Century Edinburgh', Annals of Science, Vol.32 (1975), 219-43 (235-40).

69. Foster, op.cit. note $43,162-63$.

70. Ibid., 157.

71. Ibid., $160-61$; italics in text.

72. James L. Drummond, quoted in Combe, op.cit. note 13, 39. See also Dick on astronomy:

It . . u unfolds to our view the most striking displays of the perfections of the Deity, particularly the grandeur of his Omnipotence. ... In 
short, it prepares the mind for the employments of the future world, and demonstrates, that the Creator has it in his power to distribute endlessly diversified streams of felicity, among every order of his intelligent offspring ... (Dick, op.cit. note 19, 326, 353-55).

73. Combe, op.cit. note 67, 13-14. Dick (op.cit. note 19, 398-99) lists the following areas where moral lessons may be derived from the teaching of physiology to the people: diet and regimen, cleanliness, modes of dress, the proper use of food and drink ('especially the moral and physical evils which flow from intemperance'), 'and the evils which arise from immoderate exertion of the mental or corporeal powers'.

74. Combe, op.cit. note 13,33 ; also Dick, op.cit note 19, 426-31.

75. Combe, ibid., 45.

76. But see Sumner and Coleridge, op.cit. note 45,414 :

.. . A public lecturer, who is so inclined, will find no difficulty in insinuating, together with his geometry or chemistry, the elements of infidelity and sedition. (!)

77. See, for example, George Lees, Elements of Arithmetic, Algebra, and Geometry, for the Use of the Students of the Edinburgh School of Arts (Edinburgh, 1826). The scarcity of surviving representatives of the genre is indicated by the bibliography of Tylecote, op.cit. note 1 .

78. See the following example from the Third Report of the Haddington School of Arts, quoted in A. Tyrrell, 'Political Economy, Whiggism and the Education of Working-Class Adults in Scotland 1817-40', Scottish Historical Review, Vol. 48 (1969), 151-65 (158):

Our mechanics do not sufficiently know the limits of their own, nor the extent of their masters' just rights. . . Only let the working classes be trained to discrimination, either by that general science which sharpens the faculties of all who are conversant with it; or let them be made acquainted with that particular science, part of whose object it is to elucidate the nature of the relation in which capitalists and labourers stand to each other; and we shall be as little disturbed by the spirit of combination, as by a revival of the spirit of witchcraft.

79. Brougham (1825), op.cit. note $4,5,11$.

80. Chalmers, op.cit. note $18,386-92$.

81. In 1822, when the physicist David Brewster attempted, for purely entrepreneurial reasons, to subvert the School of Arts, his strongest argument was the assertion that it 'had assumed a political character'. (The Scotsman [7 September 1822].) Nothing could, if proven, have been more effective in eliminating the hard-won support of Edinburgh's Tories. See also note 21, above.

82. More direct, less objective and highly anthropomorphic forms of moralizing natural science continued to be applied to children throughout the nineteenth century. The enormously popular 'The Reason Why', a series of Victorian science texts for children, as one example of a ubiquitous genre, topped each page with a suitably chosen Scriptural moral. This is apparent confirmation 
of the idea that people will resort to more indirect attempts at control only when they are obliged to by the demonstrated 'cleverness' of their hoped-for audience. See also: David Layton, Science for the People: The Origins of the School Science Curriculum in England (London: George Allen \& Unwin, 1973), esp. Chapters 1, 5.

83. Tyrrell, op.cit. note 78, 161, 165; [Archibald Alison], 'Progress of Social Disintegration. No. I. The Schoolmaster', Blackwood's Edinburgh Magazine, Vol. 35 (1834), 228-48 (240). The leftists in today's middle classes who fear that workers are currently deluded into acceptance of capitalism by scientific ideologies and other 'crucial' legitimations would do well to reflect on historical precedents such as this.

84. The only alternative strategy was to re-orient the curriculum directly to workers' interests and hence, per impossibile, against employers' in terests. One variant of this strategy was in fact adopted by middle-class groups. It consisted in modifying political economy into a kind of self-help doctrine, or recipe for how to rise in the world. This could purport to offer some advantage to an individual worker, while at the same time operating in the interest of the employer class as a whole, since its prescriptions could never bring success to workers collectively, and, if widely followed, would only set employee against employee.

85. Brougham (1825), op.cit. note 4,32 :

The more widely science is diffused, the better will the Author of all things be known, and the less will the people be 'tossed to and fro by the sleight of men ...'

86. Mary Douglas, Implicit Meanings: Essays in Anthropology (London: Routledge and Kegan Paul, 1975).

87. Foster, op.cit. note $43,200-01$; italics in text.

88. Ibid., 202, 205.

89. David Burns, Mechanics' Institutions: Their Objects and Tendency (Glasgow, 1837), 56-57.

90. First Report of the Edinburgh School of Arts (Edinburgh, 1822), 15.

91. See esp. Thackray, op.cit. note 10 ; Shapin, op.cit. note 10.

92. This line of speculation has been pressed a considerable way by Marxists such as Needham and Hobsbawm, and more recently by Marcuse. Other scholars, however, have tried to understand the clear historical link between science and urban, commercial and industrial societies in much broader terms. As early as 1906 Veblen was accounting for the general features of modern scientific culture in terms such as these:

In the modern culture, industry, industrial production and industrial products have progressively gained upon humanity, until these creations of man's ingenuity have latterly come to take the dominant place in the cultural scheme; and it is not too much to say that they have become the chief force in shaping men's daily life, and therefore the chief factor in shaping men's habits of thought. Hence men have learned to think in the terms in which the technological processes act. 
Arkwright's dream (see note 29, above) has, according to Veblen, been fulfilled. (Thorstein Veblen, 'The Place of Science in Modern Civilization', American Journal of Sociology, Vol.2 [1906], 585-609; repr. in Barry Barnes [ed.], Sociology of Science [Harmondsworth, Middx.: Penguin, 1972], 321-30 [327281.) We would not wish to take issue with those who see the connection between science and urban industrialization in the broadest terms, and we agree with Gellner that 'science is the mode of cognition of urban industrial societies' (Ernest Gellner, Thought and Change [London: Weidenfeld and Nicolson, 1964] , 72). It is worth noting, however, that mechanics avoided acquiring their 'habits of thought' at Mechanics' Institutes, and that the science they would have otherwise encountered there was hardly presented as the 'creation of man's ingenuity'.

93. For those to whom this work is less well-known than that of the Marxist tradition, see: M.F.D. Young (ed.), Knowledge and Control (London: Macmillan, 1971); Bernstein, op.cit. note 56; Mary Douglas, Purity and Danger (London: Routledge and Kegan Paul, 1966); idem., Natural Symbols (London: Barrie and Rockliff, 1970); idem., Implicit Meanings, op.cit. note 86.

94. David Burns, the author of the laudatory prize-essay on Mechanics' Institutions cited in note 89 , was introduced as such a person. His identification as a 'printer' is of limited value, because, as with occupational categories generally found in Institutes' lists, it is unspecified whether he was a master-printer or an employee of a master-printer. Again, it is interesting that employers' perceptions of the utility of Institutes in achieving artisan quiescence varied. One 'Master' claimed that, during a strike, not one of his men who were scientific readers was 'among the disorderly' (Tylecote, op.cit. note 1, 48-49); while 'Country Gentleman' (op.cit. note 36, 62n) referred to a 'respectable merchant at Leeds' who undertook the scientific education of selected workers, only to find that 'they all became victims to licentiousness and intemperance at an early age. The fact speaks for itself.' An excellent source for the 'failure' of the Institutes is Richard N. Price, 'The Working Men's Club Movement and Victorian Social Reform Ideology', Victorian Studies, Vol.15 (1971), 117-47.

95. See esp. Foster, op.cit. note 24.

96. We have not followed Habermas's well-known account of knowledge and interest specifically, in this paper; cf., nonetheless, his Knowledge and Human Interests (Boston: Beacon Press, 1971). 